\section{Thrombosis in a young woman: it is not what you think}

\author{
Hirenkumar Patel, Heidi Roppelt \\ Stonybrook University Hospital, \\ Stonybrook, NY, USA
}

\section{Abstract}

Hughes-Stovin syndrome is a very rare disease with fewer than 30 cases reported in the literature. This disease is characterized by the presence of pulmonary artery aneurysms in association with peripheral venous thrombosis. We report the case of a 29 -year-old woman who initially presented with a deep venous thrombosis and pulmonary embolism with subsequent pulmonary artery aneurysms. The patient developed hemoptysis and was managed with arterial embolization, lobectomy, steroids and cyclophosphamide. Hughes Stovin syndrome should be considered in the diagnosis in young men and women who present with a peripheral venous thrombosis and pulmonary artery aneurysms. The majority of cases are reported in young men, unlike our case which occured in a young woman. Anticoagulation should be avoided due to the high risk of fatality in the setting of aneurysmal rupture.

\section{Introduction}

Hughes Stovin Syndrome (HSS) is a rare disease that was first described by Hughes and Stovin in $1959 .{ }^{1}$ It is characterized by a combination of multiple pulmonary artery aneurysms and thromboembolic disease. In their original article Hughes and Stovin described four patients with fever, pulmonary artery aneurysms and a venous thrombosis. All four patients were young men and three out of the four cases had cardiac thrombi and cerebral venous thrombosis. Currently there are less than 30 cases of HSS reported in the literature. All but three cases have been reported in young men. The pathogenesis of HSS is unknown but several authors have suggested it may be a variant of Behcet's disease as pulmonary involvement is similar between HSS and Behcet's disease; however, the typical clinical manifestations of Behcet's disease such as oral/genital ulcers, arthralgias, skin lesions, iritis are absent in HSS.,2,3

\section{Case Report}

The patient is a 29-years-old Hispanic female admitted to a university hospital medical center in April 2010 with a chief complaint of hemoptysis for one day. Three months prior to this admission she was admitted for treatment of a left lower extremity deep venous thrombosis and was started on anticoagulation with warfarin. Two months prior to her admission she developed a productive cough and pleuritic chest pain. A history of low grade fevers and weight loss over last two months was also reported. One month prior to her admission she stopped warfarin because she ran out of the medication and could not renew it. Two weeks prior to her current admission she presented to a university hospital medical center complaining of a worsening cough and CT Chest angiography demonstrated acute and chronic pulmonary emboli and dilatation of segmental pulmonary arteries. Bilateral lower extremity doppler ultrasound showed findings consistent with acute and chronic thrombi. The patient was restarted on warfarin and discharged home on this medication.

She now presents to the Emergency Room with a one day history of hemoptysis, continued fevers and cough. Her history was otherwise significant for being a native of Mexico. She emigrated to the United States ten years ago and last travelled to Mexico five years ago. Her physical examination was unremarkable except for the presence of tachypnea and tachycardia. CT chest angiography showed bilateral pulmonary artery aneurysms and multiple bilateral lung infarcts (Figures 1 and 2).

Her complete blood count was noteworthy for a leukocytosis of $11,300 / \mathrm{mm}^{3}$, hemoglobin of $11.1 \mathrm{~g} / \mathrm{dL}$ and platelet count of $46,200 / \mathrm{mm}^{3}$. Erythrocyte sedimentation rate was elevated at $89 \mathrm{mg} / \mathrm{L}$. International normalized ratio was 4.1. Liver function test and renal function were normal. Pregnancy was excluded with a negative blood test. The patient was admitted to the medical intensive care unit. Subsequent in-hospital workup included the following serology: Antinuclear antibody, antineutrophil cytoplasmic antibodies, rheumatoid factor, anticardiolipin antibodies, lupus anticoagulant, RPR, Hepatitis virus panel all of which were negative. Antithrombin III was normal. More detailed history and physical exam was negative for mouth and/or genital ulcers; there was no evidence of inflammatory eye disease and no skin rash. Patient was not using any oral contraceptive agents. Transthoracic and transesophageal echocardiogram showed no major abnormalities. The patient underwent inferior vena cava filter placement. She was intubated for treatment
Correspondence: Hirenkumar Patel, Health science center $\mathrm{T}$ 16-040, Departement of Rheumatology, Stonybrook, NY 11794 USA.

Tel. +1.773.289.7005.

E-mail: hirenpatel5@live.com

Key words: vasculitis, pulmonary aneurysms, Behcet's disease.

Received for publication: 14 June 2011.

Revision received: 12 October 2011.

Accepted for publication: 25 November 2011.

This work is licensed under a Creative Commons Attribution NonCommercial 3.0 License (CC BYNC 3.0).

(C) Copyright H. Patel and H. Roppelt, 2011

Licensee PAGEPress, Italy

Rheumatology Reports 2011; 3:e14

doi:10.4081/rr.2011.e14

of massive hemoptysis. A right bronchia artery embolization was performed to control bleeding. Four days after her admission she underwent left lower lobectomy (Figure 3).

Histopathology of the pulmonary tissue and associated blood vessels showed aneurysms, luminal thrombi, parenchymal hemorrhage and active vasculitis involving large and small pulmonary arteries (Figure 4).

There were no features of granulomatous disease and no giant cells were seen. Elastic tissue stain demonstrated marked destruction and loss of elastic tissue components of the pulmonary arterial branches at the site of aneurysm formation. Specific stains for an infectious cause of the aneurysms were negative. The patient was treated with high dose steroids and intravenous monthly cyclophopsphamide with improvement in her condition. Anticoagulation was discontinued.

\section{Discussion}

The pathogenesis of HSS remains largely obscure. In the original article from Hughes and Stovin in 1959, they proposed that pulmonary artery aneurysms occur due to either degenerative changes in the bronchial arteries or due to infected emboli from organisms of low grade virulence. ${ }^{1}$ No definitive infectious cause of this disease has been identified thus far. Histopathologic findings indicate that the underlying pathogenesis consist of pulmonary vessel vasculitis which results in thrombosis, hemorrhage, infarction and aneurysm formation. Aneurysms may be single or multiple, as in our patient. One patient described in the literature also had a hepatic artery aneurysm (Table 1). ${ }^{4}$

One case report suggested hyperhomocys- 
teinemia may be involved in the formation of thrombi in HSS. ${ }^{7}$ Hughes Stovin syndrome is considered to be a variant of Behcet's disease, ${ }^{2,3}$ and these are the only two idiopathic syndromes known to predispose to the formation of pulmonary artery aneurysms. The

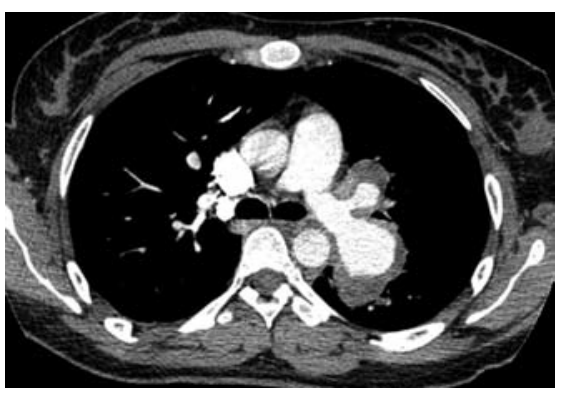

Figure 1. Large pulmonary artery aneurysms.
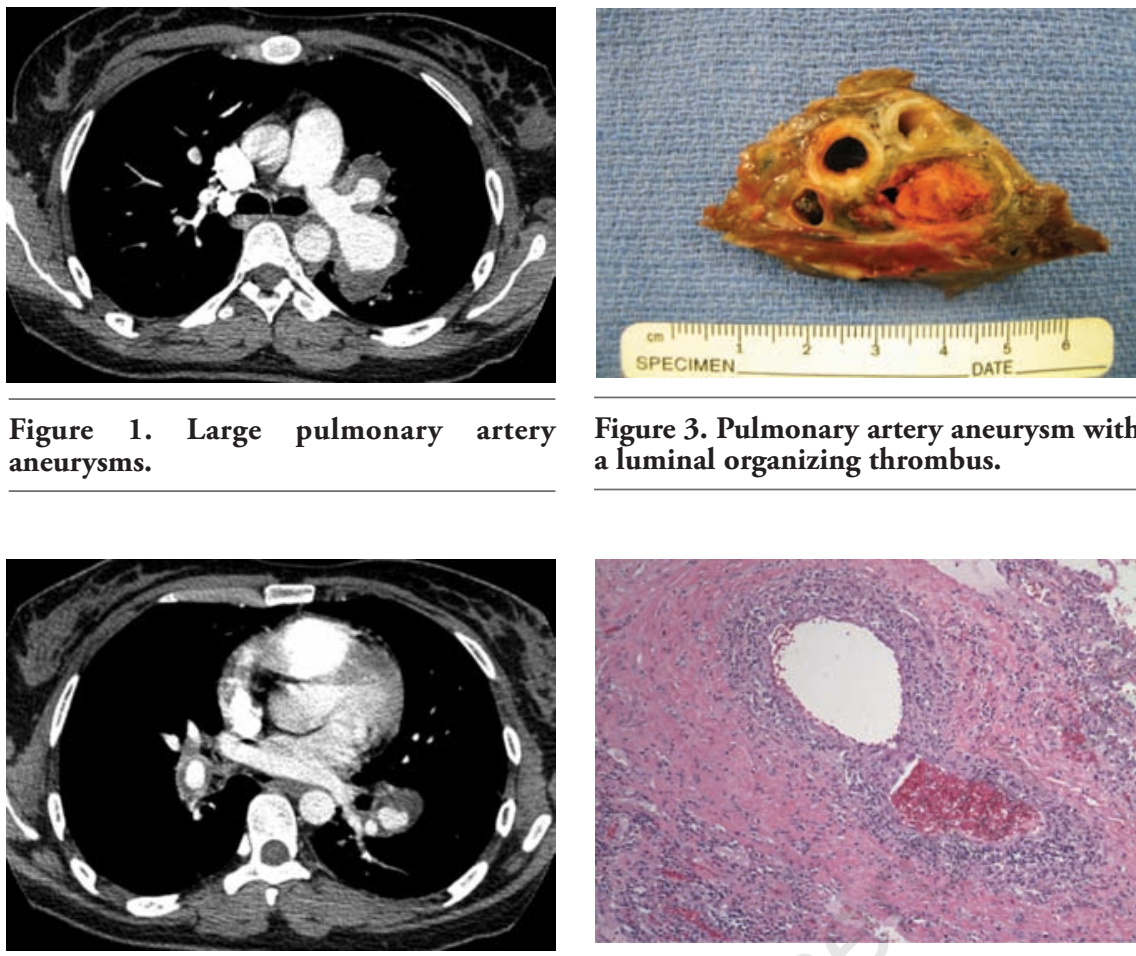

Figure 3. Pulmonary artery aneurysm with a luminal organizing thrombus.

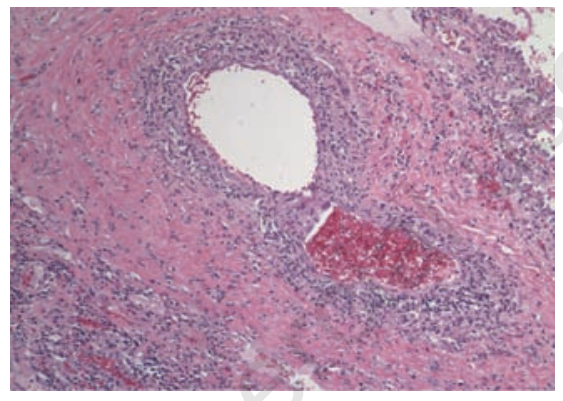

Figure 4. Acute vasculitis of a medium

sized pulmonary artery.

Figure 2. Bilateral pulmonary artery aneurysms. entation which can include chest pain, fever and cough. Dyspnea and hemoptysis are frequently a late manifestation. HSS is often fatal due to massive hemoptysis from rupture of a pulmonary artery aneurysm. Although there have been no controlled clinical trials looking at the appropriate therapy for HSS, glucocorticoid treatment in combination with immunosuppressive medications has been the mainstay of therapy. Resolution of aneurysms has been reported with cyclophosphamide treatment. ${ }^{5}$ Both oral and intravenous cyclophosphamide has been used based on isolated case reports in the literature. ${ }^{2,5}$ Cyclophosphamide is usually continued for at least one year after complete remission is achieved. Less invasive embolization of pulmonary vessels can be performed to control hemoptysis if needed. Some cases may require surgical resection of affected pulmonary segments to control bleeding. Anticoagulation should not be used in the treatment of these patients despite the formation of thrombi and antiphospholipid lipid antibodies like syndrome, due to the significant risk of pulmonary artery aneurysm rupture. While clinical sequelae of thromboses is significant (CNS infarcts, pulmonary infarcts etc.), the risk of death from rupture of a pulmonary artery aneurysm while on anticoagulation may be greater. One case of severe vascular involvement of the pulmonary vessels in a patient with Behcet's syndrome suggested treatment with infliximab may be effective when cyclophosphamide has failed. ${ }^{9}$

Table 1. Summary of a selection of published cases of Hughes Stovin Syndrome.

\begin{tabular}{|c|c|c|c|c|c|c|c|}
\hline Age/Sex & Fever & $\begin{array}{c}\text { Brain } \\
\text { involvement }\end{array}$ & $\begin{array}{l}\text { Systemic } \\
\text { artery } \\
\text { involvement }\end{array}$ & $\begin{array}{l}\text { Pulmonary } \\
\text { artery } \\
\text { aneurysms }\end{array}$ & $\begin{array}{c}\text { Heart } \\
\text { involvement }\end{array}$ & $\begin{array}{l}\text { Use of } \\
\text { Steroids in } \\
\text { treatment }\end{array}$ & $\begin{array}{l}\text { Cytotoxic } \\
\text { agent used } \\
\text { in treatment }\end{array}$ \\
\hline
\end{tabular}

Hughes and Stovin ${ }^{1}$ (1958)

Case 1

$35 / \mathrm{Male}++$

Bilateral Endocardial fibrosis N/A

N/A

\begin{tabular}{|c|c|c|c|c|c|c|c|c|}
\hline $\begin{array}{l}\text { Hughes and Stovin }{ }^{1} \text { (1958) } \\
\text { Case } 2\end{array}$ & 14/Male & + & + & $\begin{array}{l}\text { +(Internal carotid } \\
\text { artery aneurysm) }\end{array}$ & Bilateral & RA and RV thrombus & N/A & N/A \\
\hline S. Herb et al. ${ }^{4}(1998)$ & 25/Male & + & N/A & $\begin{array}{c}\text { +(L hepatic artery } \\
\text { aneurysm) }\end{array}$ & Bilateral & $\mathrm{N} / \mathrm{A}$ & + & N/A \\
\hline
\end{tabular}

\begin{tabular}{|c|c|c|c|c|c|c|c|c|}
\hline $\begin{array}{l}\text { Emad et al. }{ }^{2} \text { (2007) } \\
\text { Case } 1\end{array}$ & 26/Male & N/A & N/A & N/A & Bilateral & N/A & + & $\begin{array}{c}\text { Pulse } \\
\text { cyclophos- } \\
\text { phamide }\end{array}$ \\
\hline $\begin{array}{l}\text { Emad et al. }{ }^{2} \text { (2007) } \\
\text { Case } 2\end{array}$ & 16/Male & $\mathrm{N} / \mathrm{A}$ & + & N/A & Bilateral & $\mathrm{N} / \mathrm{A}$ & + & Azathioprine \\
\hline Lee et $_{\text {al. }}{ }^{5}$ (2008) & 48/Male & + & N/A & N/A & Bilateral & N/A & + & $\begin{array}{l}\text { Oral cyclophos- } \\
\text { phamide }\end{array}$ \\
\hline Chalazonitis et al. ${ }^{6}$ (2009) & 18/Male & - & + & N/A & Unilateral & $\mathrm{N} / \mathrm{A}$ & + & N/A \\
\hline Kim et al. ${ }^{7}(2010)$ & 24/Male & N/A & N/A & N/A & \multicolumn{2}{|c|}{ Bilateral +(RA and RV thrombus) } & + & N/A \\
\hline Al-Jahdali et al. ${ }^{8}(2010)$ & 23/Female & + & + & N/A & Bilateral & +(RV mass) & + & Azathioprine \\
\hline
\end{tabular}

N/A, not available; RA, right atrium; $R V$, right ventricle. 


\section{References}

1. Hughes JP, Stovin PG. Segmental pulmonary artery aneurysms with peripheral venous thrombosis. Br J Dis Chest 1959; 53:19-27.

2. Emad Y, Ragab Y, Shawki Ael H, et al. Hughes-Stovin syndrome: is it incomplete Behcet's? Report of two cases and review of the literature. Clin Rheumatol 2007,26: 1993-6.

3. Erkan D, Yazici Y, Sanders A, et al. Is Hughes-Stovin syndrome Behcet's dis- ease? Clin Exp Rheumatol 2004;22:S64-8.

4. Herb S, Hetzel M, Hetzel J, et al. An unusual case of Hughes-Stovin syndrome. Eur Respir J 1998;11:1191-3.

5. Lee J, Noh JW, Hwang JW, et al. Successful cyclophosphamide therapy with complete resolution of pulmonary artery aneurysm in Hughes-Stovin syndrome patient. Clin Rheumatol 2008;27:1455-8.

6. Chalazonitis AN, Lachanis SB, Mitseas P, et al., Hughes-Stovin syndrome: a case report and review of the literature. Cases $\mathrm{J}$ 2009;2:98.
7. Kim HO, Kim HC, Park Y, et al. A case of Hughes-Stovin syndrome associated with hyperhomocysteinemia. Clin Rheumatol 2010;29:807-9.

8. Al-Jahdali H. Massive hemoptysis and deep venous thrombosis presenting in a woman with Hughes-Stovin syndrome: a case report. J Med Case Reports 2010;4: 109.

9. Benjamin Schreiber, ACR 2010 Atlanta, Thieves market presentation. Available from: http://acr.peachnewmedia.com/ store/seminar/seminar.php?seminar $=6477$ 